\title{
Computational prediction and experimental validation associating FABP-1 and pancreatic adenocarcinoma with diabetes
}

Ravi N Sharaf ${ }^{*}$, Atul J Butte ${ }^{2,3,4}$, Kelli D Montgomery ${ }^{5}$, Reetesh Pai ${ }^{5}$, Joel T Dudley ${ }^{2,3,4}$, Pankaj J Pasricha ${ }^{1}$

Background: Pancreatic cancer, composed principally of pancreatic adenocarcinoma ( $\mathrm{PaC})$, is the fourth leading cause of cancer death in the United States. PaC-associated diabetes may be a marker of early disease. We sought to identify molecules associated with $\mathrm{PaC}$ and $\mathrm{PaC}$ with diabetes (PaC-DM) using a novel translational bioinformatics approach. We identified fatty acid binding protein-1 (FABP-1) as one of several candidates. The primary aim of this pilot study was to experimentally validate the predicted association between FABP-1 with $\mathrm{PaC}$ and $\mathrm{PaC}$ with diabetes.

Methods: We searched public microarray measurements for genes that were specifically highly expressed in $\mathrm{PaC}$. We then filtered for proteins with known involvement in diabetes. Validation of FABP-1 was performed via antibody immunohistochemistry on formalin-fixed paraffin embedded pancreatic tissue microarrays (FFPE TMA). FFPE TMA were constructed using148 cores of pancreatic tissue from 134 patients collected between 1995 and 2002 from patients who underwent pancreatic surgery. Primary analysis was performed on 21 normal and 60 pancreatic adenocarcinoma samples, stratified for diabetes. Clinical data on samples was obtained via retrospective chart review. Serial sections were cut per standard protocol. Antibody staining was graded by an experienced pathologist on a scale of 0-3. Bivariate and multivariate analyses were conducted to assess FABP-1 staining and clinical characteristics.

Results: Normal samples were significantly more likely to come from younger patients. PaC samples were significantly more likely to stain for FABP-1, when FABP-1 staining was considered a binary variable. Compared to normals, there was significantly increased staining in diabetic PaC samples $(p=0.004)$ and there was a trend towards increased staining in the non-diabetic PaC group $(p=0.07)$. In logistic regression modeling, FABP-1 staining was significantly associated with diagnosis of $\mathrm{PaC}(\mathrm{OR} 8.695 \% \mathrm{Cl} 1.1-68, \mathrm{p}=0.04)$, though age was a confounder.

Conclusions: Compared to normal controls, there was a significant positive association between FABP-1 staining and $\mathrm{PaC}$ on FFPE-TMA, strengthened by the presence of diabetes. Further studies with closely phenotyped patient samples are required to understand the true relationship between FABP-1, $\mathrm{PaC}$ and $\mathrm{PaC}$-associated diabetes. A translational bioinformatics approach has potential to identify novel disease associations and potential biomarkers in gastroenterology.

\footnotetext{
* Correspondence: rsharaf@stanford.edu

'Department of Gastroenterology and Hepatology, Stanford University School of Medicine, Alway Building, Room M211, 300 Pasteur Drive, MC: 5187, Stanford, CA, 94305-5187, USA

Full list of author information is available at the end of the article
} 


\section{Background}

Pancreatic cancer, composed principally of pancreatic adenocarcinoma $(\mathrm{PaC})$, is the fourth leading cause of cancer death in the United States. At diagnosis, more than $85 \%$ of patients with $\mathrm{PaC}$ have unresectable disease, with a median survival of 4-6 months [1,2].

$\mathrm{PaC}$ is a diabetogenic state with $45-65 \%$ of $\mathrm{PaC}$ patients having diabetes mellitus (DM). New-onset DM, occurring within approximately 2 years prior to cancer diagnosis, may be a paraneoplastic effect of the tumor itself secondary to a circulating tumor-associated protein that causes insulin resistance and beta-cell dysfunction [3]. Adult patients with new onset DM have an 8-fold increased risk of developing $\mathrm{PaC}$ [4]. Given that this $\mathrm{PaC}$-associated DM often occurs when the cancer is asymptomatic and resectable, it may be a useful marker of early disease, though it is difficult to clinically distinguish from chronic type II diabetes mellitus [3].

Several strategies have been used to identify pancreatic cancer-associated diabetogenic factors, including microarray work, genotyping, quantitative real time polymerase chain reaction, immunohistochemistry, serum analysis, gel electrophoresis and cell culture, and serum radioimmunoassay. These have yielded putative biomarkers, including connexin-26, insulin gene promoter polymorphisms, glucagon/insulin ratio, S1000-A8 calcium binding protein, islet amyloid polypeptide, and insulinlike growth factor-I [5-10]. None have proven definitive. The challenge is in identifying a molecule that is specifically upregulated in pancreatic adenocarcinoma that simultaneously leads to diabetes.

We sought to identify molecules associated with $\mathrm{PaC}$ and $\mathrm{PaC}$ with diabetes $(\mathrm{PaC}-\mathrm{DM})$ using an integrative genomics approach, building from our previous methods in intersecting publicly-available gene expression measurements to find DNA variants associated with disease $[11,12]$. We identified fatty acid binding protein-1 (FABP-1) as one of several candidate molecules. The primary aim of this pilot study was to experimentally validate the predicted association between FABP-1 and $\mathrm{PaC}$ and $\mathrm{PaC}$ with diabetes.

\section{Methods}

\section{Integrative Genomics}

We have previously described the creation of a database of gene expression microarray experiments across human diseases, built from publicly-available repositories [13]. Specifically, gene expression microarray experiments in the NCBI Gene Expression Omnibus (GEO) characterizing human disease conditions were automatically identified using a method where the Medical Subject Heading $(\mathrm{MeSH})$ terms attributed to publications associated with GEO experiments are were evaluated for disease concepts using the Unified Medical Language System (release $2007 \mathrm{AC}$ ) [14,15]. Each of these experimental data sets determined to be relevant to a human disease based on associated $\mathrm{MeSH}$ disease concepts was subject to automated annotation of the disease condition, the tissue or biological substance from which the samples were derived, and whether or not the experiment measured a normal control state complimentary to the annotated disease state. The automated annotation step was performed using a previously published method that analyzes particular annotations in a GEO DataSet, which is a higher-order representation of an experiment in GEO that groups experimental samples into logical subsets (e.g. "control" and "treatment") using a free-text vocabulary [16]. The disease and tissue annotations were manually reviewed in a post-processing step to ensure accuracy.

Our resulting data set incorporates over 200 diseases studied across over 350 GEO datasets comprising nearly ten thousand individual microarrays, studied in over 100 tissues. For every gene in the genome measured across microarray platforms, we calculated a change in rank normalized expression level in that gene from normal samples to disease samples, resulting in a calculated measure ranging from +1.0 (a gene changing from lowest measured expression level in normal samples to highest measured expression level in disease samples) to -1.0 (a gene changing from highest measured expression level in normal samples to lowest measured expression level in disease samples).

Within this database of disease-related gene expression changes, we searched for genes selectively upregulated in pancreatic tissue from pancreatic adenocarcinoma, but not in pancreatic tissue from samples with acute pancreatitis and type I diabetes mellitus; comparison groups were limited to those conditions with robust available GEO data.

Of those genes selectively fitting this profile, the rank normalized expression level for the top ten genes ranged from 0.19-0.12 with FABP-1 measuring 0.14, fifth on the list.

We then compared this list of genes selectively upregulated in pancreatic tissue from pancreatic adenocarcinoma with that of genes known to be associated with type II DM from the NIH Genetic Association Database http://geneticassociationdb.nih.gov/. Type II DM susceptibility genes were compared given the similar phenotype in pancreatic cancer-associated diabetes of beta-cell dysfunction and insulin resistance [17]. Type II diabetes susceptibility genes were derived using the same bioinformatics methods described above.

With a list of genes upregulated in both pancreatic adenocarcinoma and type II DM, we then filtered for a biofluid database containing proteins known to be 
detectable in the blood or urine, integrating protein lists from the Plasma Proteome Institute, the MAPU Proteome database, and the Urinary Exosome database [11,18-20]. We narrowed our search to proteins present in serum/urine because of the likely necessity for a protein synthesized in the tumor to use the blood to reach insulin target tissues, such as fat, muscle, and liver. FABP-1 was thus chosen as a candidate for validation.

\section{Selection of Cases and TMA}

Formalin fixed paraffin embedded (FFPE) Tissue Microarrays (TMA) were constructed using 148 cores of pancreatic tissue from 134 patients collected by the Stanford University Department of Pathology between 1995 and 2002 from patients who underwent pancreatic surgery. The FFPE TMA were constructed in 2004 using a manual tissue arrayer (Beecher Instruments, Silver Spring, Maryland, United States) following previously described techniques using $1.0 \mathrm{~mm}$ cores [21]. The cores were taken from areas in the paraffin block that were representative of the diagnostic tissue.

Figure 1 shows a flow diagram of samples included and excluded from the analysis. Excluded were 67 samples, consisting of chronic pancreatitis (13), neuroendocrine tumors (11), metastatic cancer to pancreas (9), ampullary adenocarcinoma (7), pancreatic cysts (5), cholangiocarcinoma (4), duodenal adenocarcinoma (3), and osteoclast-like giant cell tumor (1).

Biopsies of normal pancreatic tissue are not routinely obtained. Normal samples on our TMA were derived from histologically normal cores obtained from an organ that often also contained a pathologic pancreatic

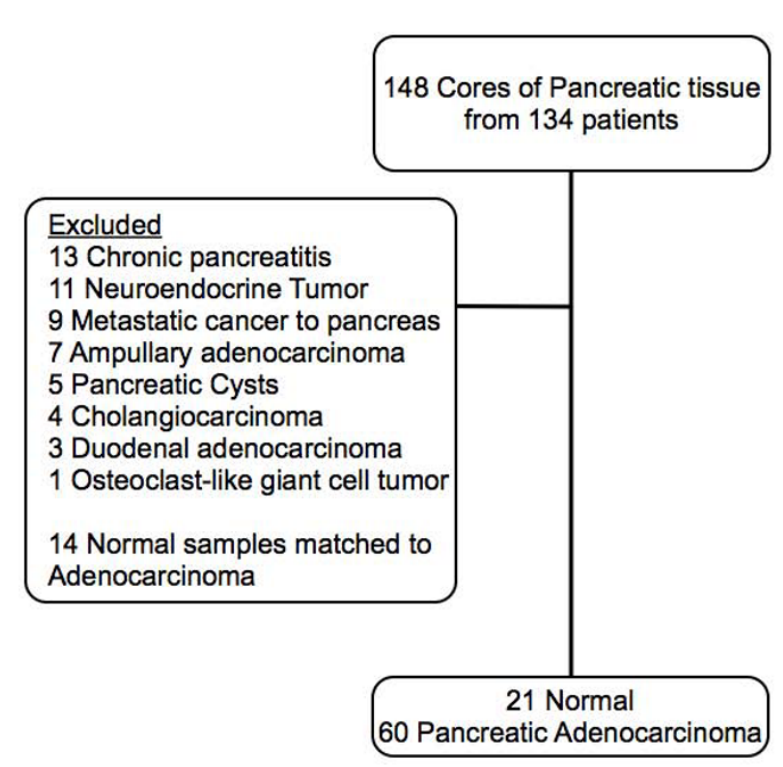

Figure 1 Study flowchart. condition. This is common practice in construction of tissue microarrays [21-23]. In this way, many normal tissues were "matched" to a given pancreatic disease state. The TMA contained 14 normal samples matched to pancreatic adenocarcinoma. In a matched analysis, it is the discordant or differentially-staining pairs that are informative for analysis. However, in our 14 normal/ pancreatic adenocarcinoma matched samples, only 4 were discordant for staining. We thus had inadequate power to conduct a matched statistical analysis. We consequently decided to compare FABP-1 staining amongst "non-matched" samples: $\mathrm{PaC}$ samples and normal samples derived from an organ that did not also contain pancreatic adenocarcinoma. Of the 21 normal samples we used in our analysis, 5 were not matched to any other pancreatic pathology. The other normal samples were matched to non PaC conditions: 8 normal/ neuroendocrine tumors, 2 normal/ampullary cancers, 1 normal/metastatic cancer to the pancreas, 4 normal/ pancreatic cysts, and 1 normal/cholangiocarcinoma. Primary analysis was performed on 21 normal and 60 pancreatic adenocarcinoma samples, stratified for diabetes.

IRB approval was obtained from the Stanford Research Compliance Office, allowing retrospective collection of patients' age, gender, presence of diabetes, alcohol and tobacco use. Clinical data was collected on a standardized form by one physician-abstractor (RNS). Clinical data was obtained from notes in a given patient's chart.

\section{Immunohistochemistry Staining and Scoring}

Serial sections of 4 um were cut from the TMA blocks, deparaffinized in xylene, and hydrated in a graded series of alcohol. The slides were pretreated with EDTA pH9 buffers for FABP-1 in a microwave step. Immunohistochemistry (IHC) staining was then performed using the DAKO EnVision + System, Peroxidase (DAB), (DAKO, Cambridgeshire, United Kingdom) for FABP-1 (1:20 dilution, Abcam, Cambridge, MA). Antibody staining was graded by a single experienced pathologist per standard protocol on a scale of $0-3(0=$ no staining, $1+=$ $1-25 \%, 2+=25-75 \%, 3+=>75 \%)$ based on the extent of cytoplasmic staining in an individual histologic core [22]. FABP-1 staining was interpreted as a binary variable $(0$ or $\geq 1)$ as well as a FABP-1score number between 0-3).

\section{Statistical Analyses}

Patient data was reported using bivariate $\left(\chi^{2}\right.$, Fishers Exact test, Wilcoxon Rank Sum with Bonferroni correction, and non parametric Kruskal-Wallis ANOVA) and multivariate analyses (logistic regression with binary outcome variables) to assess FABP-1 staining and clinical characteristics. Statistical analyses were performed using SAS Enterprise Guide 9.2 (Cary, NC). 


\section{Results}

Overall, samples were from older patients who were nondrinkers, half of whom were female, and half of whom had smoking exposure. Twenty percent of samples were derived from diabetic patients.

Table 1 shows summary statistics for our tissue sample when divided into normal and $\mathrm{PaC}$ groups. In bivariate analyses, normal samples were significantly more likely to come from younger patients. There was a trend toward normal samples being derived from patients with less tobacco exposure.

Figure 2 reveals representative pancreatic adenocarcinoma demonstrating no staining (upper left, 100x), 1+ staining (upper right 100x), 2+ staining (lower left, 100x), and 3+ staining (lower right, 200x) with FABP-1.

Table 2 describes our sample in terms of FABP-1 staining by normal tissue versus $\mathrm{PaC}$. The majority of samples in normal and $\mathrm{PaC}$ groups did not stain for FABP-1. In bivariate analyses when FABP-1 staining was considered a binary variable, $\mathrm{PaC}$ samples were significantly more likely to stain for FABP-1. There was a trend towards statistically increased staining of $\mathrm{PaC}$ samples when FABP-1 staining was interpreted as a four-level score.

In Table 3, FABP-1 staining was compared in normal and $\mathrm{PaC}$ groups, stratified for diabetes. Only 3 normal samples were derived from diabetic patients, and none stained for FABP-1. Because stratification of normals into diabetic/nondiabetic groups yielded no difference in the analysis described, the decision was made to present the normal samples as a single group of diabetics and non-diabetics.

Because the data failed to meet assumptions of normality and homogeneity of variances, we performed nonparametric Kruskal-Wallis ANOVA to compare FABP-1 staining in normal, $\mathrm{PaC}$ without $\mathrm{DM}(\mathrm{PaC}$ no $\mathrm{DM})$, and $\mathrm{PaC}$ with diabetes (PaC-DM) samples. $\mathrm{PaC}-\mathrm{DM}$ samples represent tissue from patients with

Table 1 Summary Statistics for sample ${ }^{a}$

\begin{tabular}{lccl}
\hline Characteristic & Normal Tissue $^{\mathbf{b}}$ & $\mathbf{P a C}^{\mathbf{c}}$ & $\mathbf{p}^{\mathbf{d}}$ \\
\hline Age & $59(26-79)$ & $64.5(45-79)$ & 0.007 \\
Female & $13(62 \%)$ & $28(47 \%)$ & 0.22 \\
History of Tobacco Use & $5(28 \%)$ & $27(57 \%)$ & 0.051 \\
History of Alcohol Use & $5(28 \%)$ & $20(42.6 \%)$ & 0.39 \\
Diabetes Mellitus & $3(17 \%)$ & $10(21 \%)$ & 1.00 \\
\hline
\end{tabular}

${ }^{\mathrm{a}}$ Table values are $\mathrm{n}$ (column \%) except for age which is represented as median (range). Statistical significance was taken to be $p \leq 0.05$.

${ }^{b} \mathrm{~N}=21$ for age and female characteristics, $\mathrm{n}=18$ for tobacco/alcohol/ diabetes due to missing data. Column percentages will not sum to $100 \%$. ${ }^{c} \mathrm{~N}=60$ for age and female characteristics, $\mathrm{n}=47$ for tobacco/alcohol/ diabetes due to missing data.

Column percentages will not sum to $100 \%$.

${ }^{d} \mathrm{p}$-value calculated via Wilcoxon Rank-Sum (age), Chi square (female), or Fishers exact tests (Tobacco, Alcohol, Diabetes). pancreatic adenocarcinoma-associated diabetes as well as $\mathrm{PaC}$ with coexisting chronic type II diabetes. The information to differentiate between these two groups was not available during chart review. Nonparametric analyses revealed a significant difference in FABP-1 staining (using both binary and FABP-1 score) between samples from normal, $\mathrm{PaC}$ no $\mathrm{DM}$, and PaC-DM groups, with significantly increased staining as one moves from left to right in the Table 3. The PaC-DM group had the highest percentage of FABP-1 staining. Only one normal sample stained positively for FABP-1. There was no significant difference in age between samples from $\mathrm{PaC}$ no $\mathrm{DM}$ and $\mathrm{PaC}$-DM groups that stained for FABP-1.

To elucidate relationships between the three groups, individual paired tests were conducted using the Wilcoxon Rank sum test with Bonferroni correction for multiple comparisons. There was significantly increased staining in the PaC-DM samples compared to normals $(\mathrm{p}=0.004)$ and there was a trend towards significantly increased staining in the $\mathrm{PaC}$ no $\mathrm{DM}$ group versus normal $(p=0.07)$. There was no statistical difference in FABP-1 staining between $\mathrm{PaC}$ no DM and PaC-DM groups (0.09).

In logistic regression modeling, FABP-1 staining (binary) was significant associated with diagnosis of $\mathrm{PaC}$ with an odds ratio of 8.6 (95\% CI 1.1-68, $\mathrm{p}=0.004)$. Age was a confounder in this model. Patient gender did not modify the relationship between FABP-1 staining and diagnosis.

\section{Discussion}

Using methods in integrative genomics, we predicted an association between FABP-1 and pancreatic adenocarcinoma and pancreatic adenocarcinoma with diabetes. Compared to normal controls, we found a significant positive association between increased FABP-1 staining and $\mathrm{PaC}$ on FFPE-TMA, strengthened by the presence of diabetes.

FABP-1 is a cytosolic chaperone protein that is expressed in the liver, kidney, lung, and GI tract [24]. The exact role of FABP-1 has yet to be elucidated. The association of FABP-1 with pancreatic adenocarcinoma and diabetes is of interest. Plausibility of FABP-1 as biomarker for cancer comes from previous literature suggesting an association with colon, gastric, and liver cancers. The literature is variable, but loss of FABP-1 expression in colonic tissue has correlated with progression from normal colonic tissue to adenoma to carcinoma [25]. Negative FABP-1 expression in colon cancer metastases has been associated with decreased survival, and low FABP-1 expression in colon cancer has been associated with lymph node metastasis $[26,27]$. FABP-1 gene expression has been identified as a marker of circulating colorectal tumor cells via RT-PCR [28]. On the 


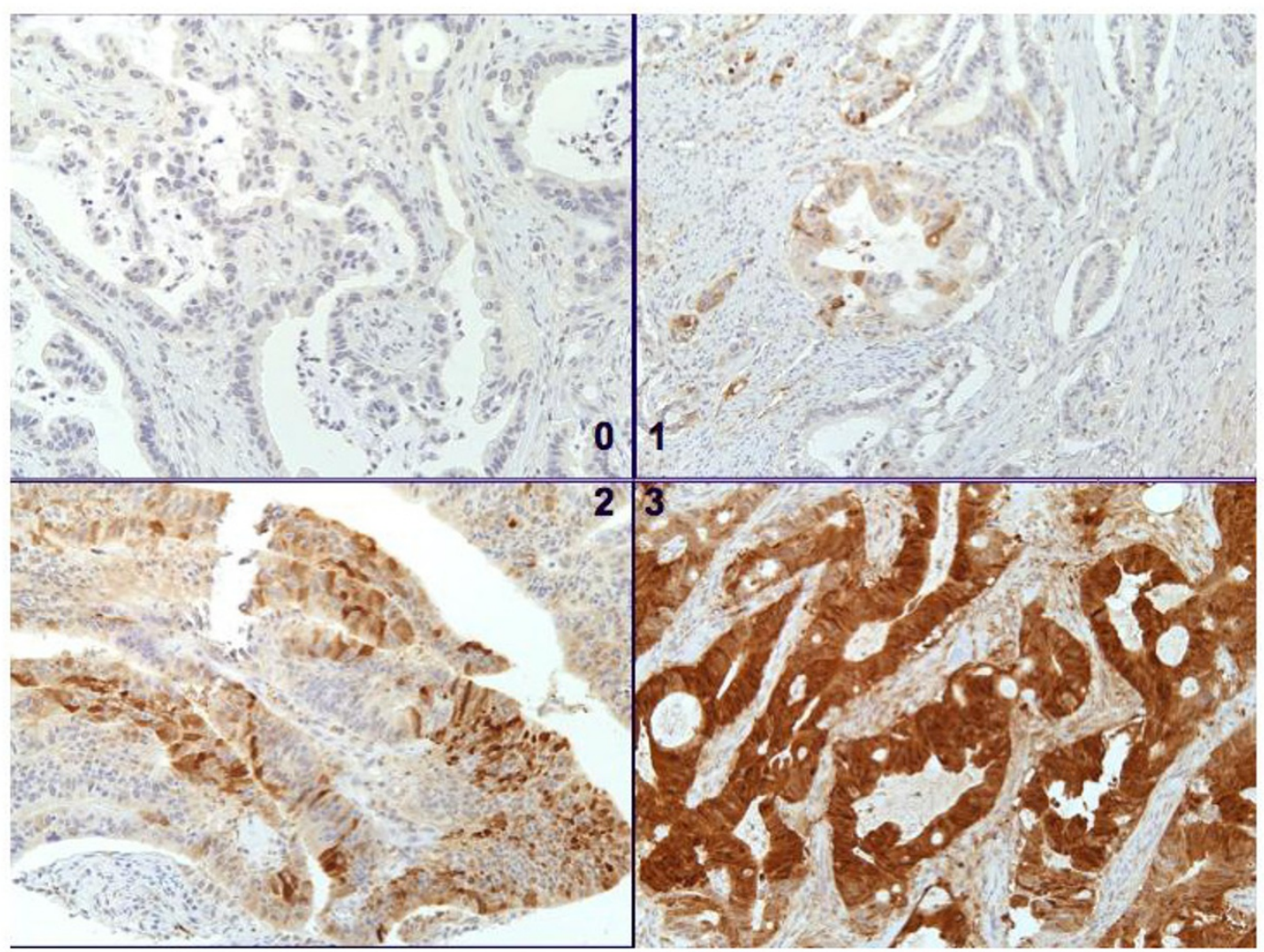

Figure 2 FABP-1 Immunohistochemistry Staining Graded from 0-3.

contrary, one study associated low FABP-1 expression in colon cancer with increased survival [29]. FABP-1 is highly expressed in gastric intestinal metaplasia and a subset of gastric adenocarcinoma [30]. In one study, half of 62 hepatocellular carcinoma samples contained L-FABP immunoreactive tumor cells [31]. A single study of gene array analysis in a cohort of 21 patients revealed FABP-1 overexpression (16x) in PaC compared to chronic pancreatitis and normal pancreatic tissue, though no further testing was performed to validate this

Table 2 Description of the Sample by Normal Tissue vs. Pancreatic Adenocarcinoma ${ }^{a}$

\begin{tabular}{cccl}
\hline Characteristic & Normal Tissue $^{\mathbf{b}}$ & $\mathbf{P a C}^{\mathbf{c}}$ & $\mathbf{p}^{\mathbf{d}}$ \\
\hline FABP-1 positive & $1(5 \%)$ & $18(30 \%)$ & 0.02 \\
FABP-1 Score & & & 0.059 \\
0: Negative & $20(95 \%)$ & $42(70 \%)$ & \\
1: $1-25 \%$ & $0(0 \%)$ & $12(20 \%)$ & \\
2: $25-75 \%$ & $1(5 \%)$ & $5(8 \%)$ & \\
3: $>75 \%$ & $0(0 \%)$ & $1(2 \%)$ & \\
\hline
\end{tabular}

${ }^{\mathrm{a}}$ Table values are $\mathrm{n}$ (column \%).

${ }^{\mathrm{b}} \mathrm{N}=21$.

${ }^{c} \mathrm{~N}=60$.

${ }^{d} p$ values represent Fisher's exact test.

${ }^{\mathrm{e}} \mathrm{FABP}-1$ positive defined as FABP-1 score $\geq 1$. association [5]. Another group using bioinformatics methods also identified FABP-1 as a candidate molecule potentially associated with $\mathrm{PaC}$, though again, no further validation was performed [32].

Plausibility of FABP-1 as a biomarker for diabetes comes from animal and human data. FABP-1 null mice demonstrate age dependent weight gain, though may be protected from obesity and hepatic steatosis when fed a saturated fat diet [33-36]. In humans, high levels of FABP-1 in placental homogenates have been associated with gestational DM [37]. Two genes with variants leading to Maturity Onset Diabetes of the Young (MODY), Hepatic nuclear factor (HNF)-4alpha and HNF-1alpha, are known to directly bind to the promoter region of FABP-1 [38]. Effects of FABP-1 are modulated through PPAR-gamma, the molecular target for the thiazolidinedione class of diabetic medications [39]. In humans, FABP-1 polymorphisms have been associated with increased levels of fasting triglycerides/LDL in females and urinary FABP-1 excretion is associated with hypertension and coronary artery disease risk factors $[40,41]$. With its up-regulation in various forms of cancer and effects on metabolism, it is plausible that FABP-1 could be a biomarker for pancreatic cancer and pancreatic cancer-associated diabetes. 
Table 3 Description of the Sample by Normal Tissue vs. PaC with and without Diabetes ${ }^{a}$

\begin{tabular}{cllll}
\hline Characteristic & Normal Tissue $(\mathbf{n}=\mathbf{2 1})$ & PaC no DM $(\mathbf{n}=\mathbf{3 7})$ & PaC-DM $(\mathbf{n}=\mathbf{1 0})$ & $\mathbf{p}^{\mathbf{b}}$ \\
\hline FABP-1 positive & $1(5 \%)$ & $9(24 \%)$ & $5(50 \%)$ & 0.02 \\
FABP-1 Score & & & & 0.02 \\
0: Negative & $20(95 \%)$ & $28(76 \%)$ & $5(50 \%)$ \\
1: $1-25 \%$ & $0(0 \%)$ & $7(19 \%)$ & $3(30 \%)$ \\
2: $25-75 \%$ & $1(5 \%)$ & $2(5 \%)$ & $1(10 \%)$ \\
3: $>75 \%$ & $0(0 \%)$ & $0(0 \%)$ & $1(10 \%)$ \\
\hline
\end{tabular}

${ }^{a}$ Table values are $\mathrm{n}$ (column \%). Due to missing data on diabetes status, the total number of patients in the PaC group was $\mathrm{n}=47$. PaC-DM represent samples from patients with pancreatic adenocarcinoma and diabetes. It was not possible to differentiate new-onset diabetics from chronic diabetics.

${ }^{\mathrm{b}} \mathrm{p}$ values represent Nonparametric Kruskal-Wallis ANOVA.

${ }^{\mathrm{C}} \mathrm{FABP}-1$ positive defined as FABP-1 score $\geq 1$.

To our knowledge, this is the first study to attempt to validate the FABP-1 association for $\mathrm{PaC}$ and $\mathrm{PaC}$ with DM. The intent of our study was to examine whether a computational approach could identify proteins associated with a particular disease, as a preliminary step in biomarker discovery. As mentioned, we narrowed our search to proteins present in serum/urine because of the postulated presence of a circulating diabetogenic factor that exerts peripheral effects. Also, a diagnostic test would necessarily be a serum/urine assay.

Of note, FABP-1 has been in detected in animal and human serum/urine and commercial ELISA-kits are available for FABP-1 serum/urine detection [42-47]. Possible mechanisms for FABP-1 presence in the serum could involve cell lysis or cellular secretion. The discovery of a biomarker for PaC-associated DM would be of immense value for the early detection and treatment of $\mathrm{PaC}$. Association by immunohistochemistry alone, however, does not necessarily translate to diagnostic utility nor causality. We have no evidence to prove that FABP1 is responsible for the pathogenesis of diabetes. Future experiments will involve larger sets of both pathologic and serum samples, with closely phenotyped patient samples to further explore this association.

Global gene expression analysis in patients with $\mathrm{PaC}$ associated DM is a complimentary and contributory approach to biomarker discovery using integrative bioinformatics. Gene expression analysis could confirm the FABP-1 overexpression we predict. There is no published literature that specifically investigates the gene expression of tumor tissue in $\mathrm{PaC}$-associated DM. Future work will be important to fill that knowledge gap.

There are several limitations of our study. When considered a binary variable, FABP-1 staining was defined as a score $\geq 1$. A more stringent cutoff for FABP-1 staining would change our reported associated with pancreatic cancer. However, we do feel that in this pilot study, grouping pancreatic cancer groups by the presence or absence of FABP-1 staining was reasonable, given that only one normal sample stained positive for
FABP-1 and that the degree of FABP-1 expression is likely to vary between tumors. The extent of FABP-1 staining will be explored in future studies with more patients samples that are better phenotyped. In multivariate analyses, age was noted to be a confounder of FABP-1 staining, though it should again be noted that only one sample in the normal group stained with FABP-1 and this sample was from a patient that was younger than the average age of the staining population in the $\mathrm{PaC}$ group. Rather than a true confounder, the association between age and FABP-1 staining may be a result of selection bias from our convenience sample or a spurious association. Larger studies are needed to further explore this relationship.

There are limitations of the bioinformatics technique itself, including potential low specificity for a given biomarker, the assumption that differential gene expression is necessarily reflected in plasma or urine, and that we excluded proteins currently not known to be detectable in serum or urine. Biomarker discovery using this methodology is necessarily limited by quantity, quality, and availability of public microarray datasets for a disease. However, it should be noted that these limitations have not precluded successful discovery of biomarkers for other diseases [12].

Our data collection was retrospective and subject to idiosyncrasies in chart documentation. We could not differentiate pancreatic cancer-associated diabetes from pancreatic cancer coexisting with chronic diabetes. The $\mathrm{PaC}-\mathrm{DM}$ group presented represents true $\mathrm{PaC}$ associated DM cases as well as those in whom the DM was unrelated to $\mathrm{PaC}$, in unknown proportions. This distinction can be elucidated in future serum FABP-1 studies with more detailed available clinical information.

Our sample was a nonrandom small convenience sample, which likely contributed to the lower than published prevalence of diabetes in $\mathrm{PaC}$, the age difference between normal and cancer groups, and the fact that we were not adequately powered to run a matched analysis [3]. However, one would expect nondifferential misclassification and a small sample size to skew results towards the null. 
The fact that a significant association between FABP-1 staining $\mathrm{PaC}$ and $\mathrm{PaC}$ with diabetes was found suggests that the true association is stronger. It would have been informative have more normal samples from diabetics to confirm lack of FABP-1 staining.

Finally, our normal samples were representative of histologically normal tissue that often did come from organs that had pancreatic pathology. We cannot rule out concerns of tumor microenvironment, though it should be noted that histologic normalcy is the basis for adequate surgical margins during tumor resection, and that this technique is standard practice in construction of microarrays and has yielded reproducible results for other types of cancer/normal tissue [22,23]. Future studies will use a control group of patients without pancreatic disease. Only one pathologist scored immunohistochemistry; however, he has several years experience. Our study would have been strengthened by having at least two independent pathologists read and score FABP-1 staining.

\section{Conclusions}

In conclusion, our study was proof of concept that a translational bioinformatics approach has potential to identify novel disease associations in gastroenterology. Further experimental and clinical research is required to understand the true relationship between FABP-1, pancreatic cancer, and $\mathrm{PaC}$-associated DM.

\section{Acknowledgements}

We gratefully thank Lisa Diamond, Alex McMillan, Julie Parsonnet, Rita Popat, and Kristin Sainani for their help in preparation of this manuscript. Partial funding for this work was provided by the National Institute for General Medical Sciences (R01 GM079719).

\section{Author details \\ 'Department of Gastroenterology and Hepatology, Stanford University School of Medicine, Alway Building, Room M211, 300 Pasteur Drive, MC: 5187, Stanford, CA, 94305-5187, USA. ²Department of Pediatrics, Stanford University School of Medicine, 300 Pasteur Drive, Room H310, Stanford, CA, 94305-5208, USA. ${ }^{3}$ Lucile Packard Children's Hospital, 725 Welch Road, Palo

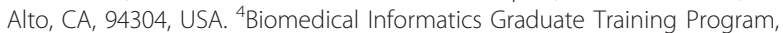 Stanford University School of Medicine, 251 Campus Drive, MSOB, x-215, MC: 5479, Stanford, CA, 94305-5479, USA. ${ }^{5}$ Department of Pathology, Stanford University School of Medicine, 300 Pasteur Drive, Lane 235, Stanford, CA, 94305-5324, USA.}

\section{Authors' contributions}

RNS, AJB, and PJP conceived of the study and its design and participated in drafting the manuscript. AJB and JTD performed the bioinformatic work. KDM performed the tissue microarray work. RP scored the stained tissue microarrays. All authors read and approved the final manuscript.

\section{Competing interests}

The authors declare that they have no competing interests.

Received: 27 July 2010 Accepted: 20 January 2011

Published: 20 January 2011

\section{References}

1. Jemal A, Siegel R, Ward E, Hao Y, Xu J: Cancer statistics, 2009. CA Cancer J Clin 2009, 59:225-249.
2. Klimstra DS: Nonductal neoplasms of the pancreas. Mod Pathol 2007 20(Suppl 1):S94-112.

3. Pannala R, Basu A, Petersen GM, Chari ST: New-onset diabetes: a potential clue to the early diagnosis of pancreatic cancer. Lancet Oncol 2009, 10(1):88-95.

4. Chari ST, Leibson CL, Rabe KG, Ransom J, de Andrade M, Petersen GM: Probability of pancreatic cancer following diabetes: a population-based study. Gastroenterology 2005, 129(2):504-511.

5. Pfeffer F, Koczan D, Adam U, Benz S, von Dobschuetz E, Prall F, Nizze H, Thiesen $\mathrm{H}-J$, Hopt UT, Löbler M: Expression of connexin26 in islets of Langerhans is associated with impaired glucose tolerance in patients with pancreatic adenocarcinoma. Pancreas 2004, 29(4):284-290.

6. Krechler T, Jachymova M, Pavlikova M, Vecka M, Zeman M, Krska Z, Svestka T, Zak A: Polymorphism -23HPhl in the promoter of insulin gene and pancreatic cancer: a pilot study. Neoplasma 2009, 56(1):26-32.

7. Kolb A, Rieder S, Born D, Giese NA, Giese T, Rudofsky G, Werner J, Büchler MW, Friess H, Esposito I, et al: Glucagon/insulin ratio as a potential biomarker for pancreatic cancer in patients with new-onset diabetes mellitus. Cancer Biol Ther 2009, 8(16):1527-1533.

8. Basso D, Greco E, Fogar P, Pucci P, Flagiello A, Baldo G, Giunco S, Valerio A, Navaglia F, Zambon C-F, et al: Pancreatic cancer-derived S-100A8 N-terminal peptide: a diabetes cause? Clin Chim Acta 2006, 372(1-2):120-128.

9. Permert J, Larsson J, Westermark GT, Herrington MK, Christmanson L, Pour PM, Westermark P, Adrian TE: Islet amyloid polypeptide in patients with pancreatic cancer and diabetes. N Engl J Med 1994, 330(5):313-318.

10. Basso D, Plebani M, Fogar P, Panozzo MP, Meggiato T, De Paoli M, Del Favero G: Insulin-like growth factor-I, interleukin-1 alpha and beta in pancreatic cancer: role in tumor invasiveness and associated diabetes. Int J Clin Lab Res 1995, 25(1):40-43.

11. Dudley JT, Butte AJ: Identification of discriminating biomarkers for human disease using integrative network biology. Pac Symp Biocomput 2009, 27-38.

12. English SB, Butte AJ: Evaluation and integration of 49 genome-wide experiments and the prediction of previously unknown obesity-related genes. Bioinformatics 2007, 23(21):2910-2917.

13. Dudley JT, Tibshirani R, Deshpande T, Butte AJ: Disease signatures are robust across tissues and experiments. Mol Syst Biol 2009, 5:307.

14. Chen R: Finding Disease-Related Genomic Experiments Within an International Repository: First Steps in Translational Bioinformatics. AMIA Annual Symposium Proceedings 2006, 106-110.

15. Bodenreider O: The Unified Medical Language System (UMLS): integrating biomedical terminology. Nucleic Acids Research 2004, 32(Database):D267-270.

16. Dudley J, Butte AJ: Enabling integrative genomic analysis of high-impact human diseases through text mining. Pac Symp Biocomput 2008, 580-591.

17. Becker KG, Barnes KC, Bright TJ, Wang SA: The genetic association database. Nat Genet 2004, 36(5):431-432.

18. Anderson NL, Polanski M, Pieper R, Gatlin T, Tirumalai RS, Conrads TP, Veenstra TD, Adkins JN, Pounds JG, Fagan R, et al: The human plasma proteome: a nonredundant list developed by combination of four separate sources. Mol Cell Proteomics 2004, 3(4):311-326.

19. Zhang $Y$, Zhang $Y$, Adachi J, Olsen JV, Shi R, de Souza G, Pasini E, Foster LJ, Macek B, Zougman A, et al: MAPU: Max-Planck Unified database of organellar, cellular, tissue and body fluid proteomes. Nucleic Acids Res 2007, 35(Database):D771-779

20. Pisitkun T, Shen R-F, Knepper MA: Identification and proteomic profiling of exosomes in human urine. Proc Natl Acad Sci USA 2004, 101(36):13368-13373.

21. Marinelli RJ, Montgomery K, Liu CL, Shah NH, Prapong W, Nitzberg M, Zachariah ZK, Sherlock GJ, Natkunam Y, West RB, et al: The Stanford Tissue Microarray Database. Nucleic Acids Res 2008, 36(Database):D871-877.

22. Lehman NL, van de Rijn M, Jackson PK: Screening of tissue microarrays for ubiquitin proteasome system components in tumors. Meth Enzymol 2005, 399:334-355.

23. Wapnir IL, van de Rijn M, Nowels K, Amenta PS, Walton K, Montgomery K, Greco RS, Dohán O, Carrasco N: Immunohistochemical profile of the sodium/iodide symporter in thyroid, breast, and other carcinomas using high density tissue microarrays and conventional sections. J Clin Endocrinol Metab 2003, 88(4):1880-1888.

24. Furuhashi M, Hotamisligil GS: Fatty acid-binding proteins: role in metabolic diseases and potential as drug targets. Nat Rev Drug Discov 2008, 7(6):489-503 
25. Lawrie LC, Dundas SR, Curran S, Murray Gl: Liver fatty acid binding protein expression in colorectal neoplasia. Br J Cancer 2004, 90(10):1955-1960.

26. Yamazaki T, Kanda T, Sakai Y, Hatakeyama K: Liver fatty acid-binding protein is a new prognostic factor for hepatic resection of colorectal cancer metastases. J Surg Oncol 1999, 72(2):83-87.

27. Pei H, Zhu H, Zeng S, Li Y, Yang H, Shen L, Chen J, Zeng L, Fan J, Li X, et al: Proteome analysis and tissue microarray for profiling protein markers associated with lymph node metastasis in colorectal cancer. J Proteome Res 2007, 6(7):2495-2501.

28. Smirnov DA, Zweitzig DR, Foulk BW, Miller MC, Doyle GV, Pienta KJ, Meropol NJ, Weiner LM, Cohen SJ, Moreno JG, et al: Global gene expression profiling of circulating tumor cells. Cancer Res 2005, 65(12):4993-4997.

29. Lyall MS, Dundas SR, Curran S, Murray Gl: Profiling markers of prognosis in colorectal cancer. Clin Cancer Res 2006, 12(4):1184-1191.

30. Hashimoto T, Kusakabe T, Watanabe K, Sugino T, Fukuda T, Nashimoto A, Honma K-I, Sato Y, Kimura H, Fujii H, et al: Liver-type fatty acid-binding protein is highly expressed in intestinal metaplasia and in a subset of carcinomas of the stomach without association with the fatty acid synthase status in the carcinoma. Pathobiology 2004, 71(3):115-122.

31. Suzuki T, Watanabe K, Ono T: Immunohistochemical demonstration of liver fatty acid-binding protein in human hepatocellular malignancies. J Pathol 1990, 161(1):79-83.

32. Harsha HC, Kandasamy K, Ranganathan P, Rani S, Ramabadran S, Gollapudi S, Balakrishnan L, Dwivedi SB, Telikicherla D, Selvan LDN, et al: A compendium of potential biomarkers of pancreatic cancer. PLOS Med 2009, 6(4):e1000046.

33. Martin GG, Atshaves BP, Mclntosh AL, Payne HR, Mackie JT, Kier AB, Schroeder F: Liver fatty acid binding protein gene ablation enhances age-dependent weight gain in male mice. Mol Cell Biochem 2009, 324(12):101-115.

34. Martin GG, Atshaves BP, McIntosh AL, Mackie JT, Kier AB, Schroeder F: Liver fatty acid-binding protein gene-ablated female mice exhibit increased age-dependent obesity. J Nutr 2008, 138(10):1859-1865.

35. Newberry EP, Kennedy SM, Xie Y, Sternard BT, Luo J, Davidson NO: Dietinduced obesity and hepatic steatosis in L-Fabp/mice is abrogated with SF, but not PUFA, feeding and attenuated after cholesterol supplementation. Am J Physiol Gastrointest Liver Physiol 2008, 294(1): G307-314.

36. Newberry EP, Xie Y, Kennedy SM, Luo J, Davidson NO: Protection against Western diet-induced obesity and hepatic steatosis in liver fatty acidbinding protein knockout mice. Hepatology 2006, 44(5):1191-1205.

37. Magnusson AL, Waterman IJ, Wennergren M, Jansson T, Powell TL: Triglyceride hydrolase activities and expression of fatty acid binding proteins in the human placenta in pregnancies complicated by intrauterine growth restriction and diabetes. J Clin Endocrinol Metab 2004, 89(9):4607-4614

38. Rowley CW, Staloch $\amalg$, Divine JK, McCaul SP, Simon TC: Mechanisms of mutual functional interactions between HNF-4alpha and HNF-1alpha revealed by mutations that cause maturity onset diabetes of the young. Am J Physiol Gastrointest Liver Physiol 2006, 290(3):G466-475.

39. Wolfrum C, Borrmann CM, Borchers T, Spener F: Fatty acids and hypolipidemic drugs regulate peroxisome proliferator-activated receptors alpha - and gamma-mediated gene expression via liver fatty acid binding protein: a signaling path to the nucleus. Proc Natl Acad SC USA 2001, 98(5):2323-2328.

40. Fisher E, Weikert C, Klapper M, Lindner I, Möhlig M, Spranger J, Boeing H, Schrezenmeir J, Döring F: L-FABP T94A is associated with fasting triglycerides and LDL-cholesterol in women. Mol Genet Metab 2007, 91(3):278-284

41. Ishimitsu T, Ohta S, Saito M, Teranishi M, Inada H, Yoshii M, Minami J, Ono $\mathrm{H}$, Hikawa A, Shibata $N$, et al: Urinary excretion of liver fatty acidbinding protein in health-check participants. Clin Exp Nephrol 2005, 9(1):34-39

42. Portilla D, Dent C, Sugaya T, Nagothu KK, Kundi I, Moore P, Noiri E, Devarajan P: Liver fatty acid-binding protein as a biomarker of acute kidney injury after cardiac surgery. Kidney Int 2008, 73(4):465-472.

43. Lachmann RA, Werchan S, Schachtrup C, Haitsma JJ, Spener F, Lachmann B: Liver-type fatty acid binding protein in serum and broncho-alveolar lavage in a model of acute respiratory failure because of surfactant depletion-a possible marker for lung damage? Clin Physiol Funct Imaging 2006, 26(6):371-375.

44. Piumngam P, Schachtrup C, Owada Y, Kondo H, Promptmas C, Spener F: Expression of liver-type fatty acid-binding protein in murine lung and its release into serum upon challenge of lung with lipopolysaccharide. Eur $J$ Lipid Sci Technol 2005, 107(1):145-152.

45. Lifesciences U. [http://www.uscnk.com/directory/Fatty-acid-binding-protein1-Liver(FABP1)-1566.htm].

46. Biosciences L. [http://www.Isbio.com/Products/GeneDetail.aspx?LSID=1627].

47. Laboratories SC. [http://www.scbt.com/table-l-fabp.html].

\section{Pre-publication history}

The pre-publication history for this paper can be accessed here:

http://www.biomedcentral.com/1471-230X/11/5/prepub

doi:10.1186/1471-230X-11-5

Cite this article as: Sharaf et al:: Computational prediction and experimental validation associating FABP-1 and pancreatic adenocarcinoma with diabetes. BMC Gastroenterology 2011 11:5.

\section{Submit your next manuscript to BioMed Central and take full advantage of:}

- Convenient online submission

- Thorough peer review

- No space constraints or color figure charges

- Immediate publication on acceptance

- Inclusion in PubMed, CAS, Scopus and Google Scholar

- Research which is freely available for redistribution

Submit your manuscript at www.biomedcentral.com/submit
C) Biomed Central 